\title{
Das invisibilidades
}

Texto em processo, por Lucas Bambozzi

É verdade que há muita loucura em se ocupar com algo que sequer vemos. Louis-Ferndand Céline.

O invisível está em toda parte. O invisível expande-se, e demanda ser visto. Há o invisível como metáfora, como construção semântica, como poesia, como escape para o embate com a matéria. Há o invisível nos afetos, na comoção, no aperto da garganta, nas palavras que escapam, nas angústias, alegrias ou tristezas do amor.

Há o invisível dos domínios do fantástico, da magia, do desconhecido, nas noções às vezes obscuras de mistério. Há a crença no invisível que habita o sobrenatural, nos espectros, nas fantasmagorias. No que irradia dos corpos, sobretudo das coisas que insistem em se mostrar latentes e vivas.

Há o invisível na literatura, no que exala dos sabores e aromas de Proust, nas ruas e passagens de Baudelaire, nas forças da noite de J-F Céline, no esforço em enxergar a crueldade exultante nos Cantos de Maldoror, no embate entre o real e seu duplo de Clément Rosset. Há uma sugestão ilusória na criação com palavras, fictícia e irreal, como em um Mallarmé, que faz ver o que seja, existente ou não, para além do ceticismo dos olhos.

Há toda uma filosofia que se ocupa desse invisível que se mostra paradoxal, desafiador das formas de ver. Pois claro, há um invisível no pensamento filosófico, na caverna de sombras de Platão, no traços de um rosto descrito por Wittgenstein, na compreensão do corpo e da alma por parte de Hannah Arendt (ah, o pensar, quanto de invisível carrega este ato!). 
Há espectros que se fazem ouvir. Pois sim, há toda uma escuta do que se supõe existir, e que suplante a credulidade da visão, seja nos escritos ou nas captações de áudio de Hilda Hilst. Seja pelos espíritos, pelos corpos visíveis ou pelos que nos habitam, somos movidos pelo que não vemos, mas muitas vezes ouvimos. Algo perfeitamente mensurável, por radinhos de pilha que detectam interferências eletromagnéticas ou vozes de uma outra dimensão, ou por torres radiotelescópicas que captam corpos lunares e estelares. Pois há, a ciência às vezes concorda com certas premissas místicas e/ou exotéricas, uma enorme gama de frequências inaudíveis, que não se escuta, e que supostamente são vitais ao funcionamento de nossos corpos neste planeta. ${ }^{1}$

As representações visuais do espectro circulam há tempos entre nós. Em Goya está em "Que viene el Coco" (gravura em água-forte, 1799) e em outros da série Los Caprichos. Há o invisível na iconografia científica do final do século XIX, quando surgiram inúmeras tentativas de capturar os espíritos, a aura ou os espectros, em uma variada gama de máquinas de ficção ${ }^{2}$. Há a crença no que se quer ver, como no devir fantasma dos corpos fotografados.

Há a materialização do invisível da radioatividade humana, da aura, do efeito Kirlian e do Perianto $^{3}$. Há o invisível implícito na fotografia mortuária, permeada por nimbos, auréolas, aura, véus, lençóis e outros elementos típicos da representação de espectros. Há o invisível nas premissas do tipo "só-vejo-o-que-acredito-ver" e na incredulidade do "sóacredito-vendo".

\footnotetext{
${ }^{1}$ Dentre outras referências vale conferir o documentário "Resonance: Beings of Frequency" (Ressonância: Somos Seres de Frequência), que descreve uma teoria segundo a qual a frequência Alfa emitida pelos nosso cérebros, gravadas por Hans Berger por meio de eletroencefalografia, por ele criada em 1924, são similares e estariam em harmonia com a Ressonância Schumann, definidas por Otto Schumann em 1952, que equivale à frequência emitida pelo planeta Terra, de 7,83Hz. https://www.youtube.com/watch?v=xtpkveNYBtA

2 Philippe Dubois denomina "fantas(má)ticas máquinas de ficção" ao se referir ao conjunto de experiências com a fotografia do corpo e suas fantasmagorias na segunda metade do século XIX, em um período afetado por um cientificismo positivista e eufórico. ${ }^{3}$ Efeito Kirlian refere-se ao processo fotográfico desenvolvido pelo casal soviético Semyon e Valentina Kirlian em 1939 , inicialmente denominado "fotografia de campo radiante" e Perianto foi o termo utilizado pelo padre e inventor gaúcho Ignácio Landell de Moura (1861-1928) para descrever o efeito produzido pela eletricidade humana em chapas radiográficas.
} 
Há também invisibilidades de outras sutilezas, como nos desvios para o invisível através da interioridade, da profundidade, em certo impulso para uma espiritualidade imaterial "pictórica" em Yves Klein, em Rothko. Há o jogo do visível/invisível nas telas brancas ou nos traços apagados por Rauschemberg, nos silêncios induzidos de John Cage, nas pinturasinstruções de Yoko Ono, na tensão que antecede os happenings e as performances.

Pois na ordem da comunicação, pois sim reiteradamente tratamos aqui de linguagem, de algo que oscila em arte e comunicação, há sempre o indizível, que resvala na troca de correspondências, nas retóricas, na supressão das evidências materiais, no que é colocado como faltante, no que falta de fato, no que é menos que informação, pois se atém a ser sugestão, entrelinha ou direcionamento de atenção. E já que o indizível não é o que se cala há o buraco do não-dito entre esses termos.

Há o invisível que se traveste semanticamente de incorporal, de imaterial, de desmaterializado, pensado no campo da produção cultural como inserção, estratégia, manifesto, movimento, onda, discurso, apelo, zeitgeist, sinal dos tempos ou simplesmente como forma de dar "visibilidade" a uma cena invisível. ${ }^{4}$

Há um invisível, assim denominado, simplesmente porque "o informe e o indistinto nos escapam" (CAUQUELIN, 2006, p. 146), e assim persiste sendo propagado.

Há o invisível engastado em lugares, e que enuncia presenças nas vibrações, tremores, vestígios, legados, rastros, memórias, ventos e cheiros.

\footnotetext{
${ }^{4}$ Haveria uma grande lista de exposições que marcaram a adoção do termo "invisibilidade" como um movimento conduzido por artistas e/ou curadores como forma de enunciar uma cena. Dentre estas,a exposição Os Imateriais, mostra-manifesto organizada por Jean-François Lyotard no Centro Georges Pompidou em 1985, é das mais célebres. A presente pesquisa incluirá em seus anexos uma lista com dezenas de outras exposições e mostras ligadas ao tema.
} 
Ver tudo isso demanda atenção. "Sem esse recolhimento contemplativo, o olhar perambula inquieto de cá para lá e não traz nada a se manifestar (HAN, 2015, p. 36). E se Cézanne via o perfume das coisas é porque dedicava atenção profunda à visualização das coisas nem sempre visíveis.

É esse o invisível, fruto da atenção, da escuta, do olhar redobrado que habita o espaço, prenhe e impregnável de imaginação, que "aumenta os valores da realidade" (BACHELARD, 1989), pois sim, a imaginação é um disparador de estímulos que faz notar os cantos e as visões não reveladas de um lugar.

Há o lugar do eletrônico e do digital, um lugar incerto, seguramente vazio, definido por protocolos, impulsos numéricos, apagável, em constante obsolescência, mero suporte físico, em estado contínuo de reiteração tecnicista e de notada desolação, em ansiosa agonia, mesmo que desprovido de qualquer humanismo.

Há invisibilidades pois na suposta imaterialidade das projeções de cinema e vídeo, nas ressignificações sugeridas de tais projeções em espaços públicos, variando o sentido entre o lugar da coisa, da arquitetura e da imagem em suas superfícies, em notável estado de instabilidade e impermanência.

Há o invisível porque há somas e subtrações demais no mundo, em aritméticas, razões e exponenciais que não alcançamos.

Há a estratégia de invisibilidade ideológica na política, nas táticas de poder, nas formas de dominação social, na exploração econômica, na lógica colonialista, na hegemonia branca e heteronormativa, nas questões de gênero, na presença constrangedora do pensamento segregacionista. Há muito desse invisível na miséria, no desamparo, na míngua que se 
multiplica tanto que se torna sórdida - da mesma estirpe daquela invisibilidade produzida pela hierarquização artificiosa entre as raças, etnias, cores de pele e credos, que se escolhem manter abaixo das zonas de visibilidade social.

Há o invisível que se dá pela incapacidade de ver, há o invisível tal como o vemos.

Há o invisível que interessa ser debatido e o que não interessa de modo algum, entrelaçando tensões ideológicas, pois há sempre interesses inconfessáveis.

Há o invisível nas argumentações, nas dissertações, nos ensaios, nas obras inventadas, nos sebos, nas páginas rasgadas, nos textos difíceis de ler e nas noites de insônia. Há falta de visibilidade mais que invisibilidade, para ver e compreender as coisas mal vividas ou sofridas, as escolhas difíceis, as eleições afetivas, os embates, as dúvidas.

Há um ponto cego, invisível, nas tecnologias de visão implementadas em máquinas de inteligência artificial, um invisível 'maquínico' que nos olha, nos espreita e nos classifica. E sempre devem haver formas de resistir aos meios de codificação do visível previsto pelas máquinas de visão, assim como há (ou sempre há de haver) formas de escapar do escrutínio e do escaneamento técnico por subversão ou pela linguagem da subjetividade e por mais que as máquinas também almejem a subjetividade há a relativização do que é visível ou nem tanto.

Há que se enxergar o que circula entre o que não se vê e o que é essencialmente visível. Há também que se perceber o quanto o não enxergar, o não saber, a indefinição do fato ou da informação, hoje é parte de um enigma que nos é colocado às vezes perversamente, em espetáculo continuado. Há, nos espetáculos, como se sabe, o visível pueril, assim como há o invisível obsceno, que está fora da cena. 
E há claro, uma política implícita ou disfarçada nos sistemas informacionais atuais, no controle das redes, nos sinais wi-fi, entre sistemas pseudo-compartilhados, na infraestrutura das redes, nas torres de celulares, nas emissões de rádio, nos walkie-talkies dos seguranças nos shoppings, nas portas dos restaurantes, nas guaritas, nas ruas. Enxergar esse invisível, que constitui também o locus da política, é entender o constituinte primordial de um lugar ou espaço.

Pois há que se contornar o obstáculo da invisibilidade, "tornando visível a ausência de visibilidade" (CAUQUELIN, 2006, p. 79).

Há então esse outro invisível aflitivo, que nos concerne, que é "quando ver é sentir que algo inelutavelmente nos escapa, isto é: quando ver é perder" (DIDI-HUBERMAN, 1998, p $34)$.

Há também aqui sim, o reconhecimento do ruído, do chiado, do zumbido, da estática, das oscilações de sinal, do fluxo de comunicação e da eletricidade, da eletro-osmose, da consideração do invisível e suas 'presenças' como propostas estéticas.

Há muitos e variados invisíveis, plurais demais para serem listados, cuja aptidão, vocação, tendência, qualidade, assombro ou beleza, é serem mantidos tal como o são, invisíveis.

Igualmente parece ser favorável crer que "o que se vê provém do que não é aparente" frase atribuída a Paulo de Tarso, o apóstolo São Paulo, segundo Paul Virilio (1993, p. 68), já que a imaterialidade do espaço informacional emergente tem a ver com alguma metafísica. 
Faltaria ainda: "fecha o olhos e vê", como nos aconselha Joyce, em seu Ulysses. ${ }^{5}$

Enfim, há aqui uma disposição em neutralizar o aspecto possivelmente negativo do fabular sobre algo que não existe, "a arte de sugerir algo sem evocar nada preciso" nas palavras de Clément Rosset a respeito do jogo estético, para fazer valer "a virtude positiva de permitir uma criação poética" (2013). Para além de um êxito dessa ordem, o invisível tratado aqui tem espessura, densidade, comprimento de onda, pulsação e capacidade de penetração nos corpos e matérias matematicamente mensuráveis e distinguíveis. Do que se constitui esse invisível, que espaços transita ou habita, de qual ordem ou natureza é composto, e de algumas ideias de "como ver", é do que tratamos nas próximas páginas.

\section{Referências bibliográficas (deste capítulo)}

ARENDT, Hannah. A Vida do Espírito. Rio de Janeiro: Relume - Dumará. 1991. p. 22-25

CAUQUELIN, Anne. Frequentar os incorporais. Constribuição a uma teoria da Arte Contemporânea. São Paulo: Martins Fontes, 2006.

CERTEAU, Michel de. A Invenção do Cotidiano, Vı. Petrópolis: Ed. Vozes, 2000.

DUBOIS, Plilippe. O Corpo e seus fantasmas, in O ato fotográfico Campinas: Papirus, 1993. p. 219-247.

FLUSSER, Vilém. Filosofia da caixa preta - Ensaios para uma futura filosofia da fotografia. São Paulo: Hucitec, 1985.

FOUCAULT, Michel. De outros espaços - Conferência proferida por Michel Foucault no Cercle d'Études Architecturales, em 14 de Março de 1967. Tradução de Pedro Moura, 1986.

ROSSET, Clément. Lo invisible, Buenos Aires: El Cuenco de Plata, 2014.

${ }^{5}$ JOYCE, James. Ulysses. Rio de Janeiro: Civilização Brasileira, 1966, p. 41-42. 